\title{
Nurses knowledge related to adverse drug reaction reporting and associated factors at Felegehiwot Referral Hospital and University of Gondar Teaching Hospital, Northwest Ethiopia
}

\author{
Abewa Adimasu \\ College of Medical and Health sciences, Debremarkos, Ethiopia \\ Email address: \\ gebretsadek@yahoo.com
}

\section{To cite this article:}

Abewa Adimasu. Nurses Knowledge Related to Adverse Drug Reaction Reporting and Associated Factors at Felegehiwot Referral Hospital and University of Gondar Teaching Hospital, Northwest Ethiopia. American Journal of Health Research.

Vol. 2, No. 4, 2014, pp. 164-170. doi: 10.11648/j.ajhr.20140204.20

\begin{abstract}
Background: Even though some adverse drug reactions are minor and can be resolved quickly, some can cause permanent disability or death. Inadequate knowledge of adverse drug reactions by Nurses is a common problem of any pharmacovigilence programs. Objective: The objective of this study is to assess predictors of Nurses knowledge related to adverse drug reaction reporting at Felegehiwot Referral Hospital and University of Gondar Teaching Hospital, Northwest Ethiopia. Methods - Hospital based cross sectional study was conducted from March 11, 2013 to April 12, 2013. A total number of 214 Nurses involved in this study. Self-administered pre-tested questionnaire was used. Stratified random sampling technique was used to select study participants. Bivariate analysis and multivariable logistic regression analyses were employed for identifying inadequate knowledge regarding adverse drug reaction reporting. Results: Mean age of the respondents21.8 years $(\mathrm{SD}=7.01)$. One hundred twenty two $(57.0 \%)$ of the respondents were females, $152(71.7 \%)$ participants' level of education were bachelor of Nurse. The participants mean of experience were 1.64 $(\mathrm{SD}=4.7)$ years. One hundred one $(99.0 \%)$ participants had inadequate knowledge on how to report adverse drug reaction and Nurses who categorized in the age of 26-35 years was 10.4 times more likely inadequate knowledge $(\mathrm{AOR}=10.4,95 \% \mathrm{CI}=86.423$ 1.251, $\mathrm{P}=0.030$ ). Conclusions and recommendation: Nurses were inadequate knowledge on adverse drug reaction reporting. So Food, Medicine, Health Care Administration and Control Authority of Ethiopia should prepare training and continual education related to adverse drug reaction reporting for Nurses.
\end{abstract}

Keywords: Predictor, Knowledge, Pharmacovigilance, Ethiopia

\section{Introduction}

Adverse drug reaction is defined as noxious and unintended effects resulting not only from the authorized use of a medicinal product at normal doses, but also from medication errors and uses outside the terms of the marketing authorization, including the misuse and abuse of the medicinal product(1).

Adverse drug reactions have been regarded as worldwide major public health problem since they represent a sizable percentage of admissions, death and an economic burden (2).

A study in United States of America revealed that 108,000 Americans died in hospitals from adverse reactions to food and drug authority of America-approved drugs properly administered by licensed medical professionals(3). In the same year, 2.2 million Americans had adverse reactions to food and drug authority of America-approved drugs (3).

A study conducted in South Africa of secondary hospital $6.3 \%$ of medical admissions were due to an adverse drug reaction, which is similar to proportions found in developed countries (4).

The burden of incidence of adverse drug reactions on health care and patients in Ethiopia not available but, it is likely that the problem is considerable in, with widespread irrational drug use, including preference for injections, misuse of antibiotics and other traditional/herbal medicines 
and extensive self-medication (5).Studies have shown that the Ethiopian population has a distinct genetic makeup compared to Caucasian, Oriental or other Black populations that results higher probability of getting adverse drug reaction(6).

The finding of the studies performed at China (7),Northern India (8) and Italy (9) showed healthcare professionals knowledge on adverse drug reaction reporting was very low. A study done in Ethiopia showed that 137(26.6\%)participants had adequately answered knowledge determining questions (10).A study conducted in Southwest of Ethiopia showed that19(23.17\%) respondents had adequate knowledge on adverse drug reaction reporting (10). According to the available data no study has assessed Nurses knowledge related to adverse drug reaction reporting and associated factors in the study areas. So, the present study would determine level of Nurses knowledge and identifying dependent predictors for inadequate knowledge towardsadverse drug reactionreporting. Therefore this study will be used to help appropriate adverse drug reactionreporting in the health system.

\section{Participants' and Methods}

\subsection{Study Setting and Period}

This study was conducted from March 11, 2013 to April 12, 2013 at Felegehiwot Referral Hospital and University of Gondar Teaching Hospital. Finote Selam hospital and University of Gondar Teaching Hospital are located in Bahirdar and Gondar, North West of Ethiopia, respectively.

Bahirdar and Gondar are located in Amhara region approximately $565 \mathrm{~km}$ and $724 \mathrm{~km}$, located in the North West of Ethiopia away from Addis Ababa respectively.

According to the available data, there are 244 health professionals (32 Physicians, 189 Nurses and 23 Pharmacy professionals) and 654 health professionals (130 Physicians, 461 Nurses and 63Pharmacy professionals) in Finote Selam hospitaland University of Gondar Teaching Hospital, respectively.

Felegehiwot Referral Hospital is one of the regional referral hospitals in North Eastern part of Ethiopia. Itserves for people of East and West Gojjam, Bahirdar liyu and Awi, and its surroundings, south Gondar zones.The hospital has a total 284 beds. It has 275 technical and 187 administrative staffs.

The University of Gondar Teaching Hospitalhas the only referral teaching hospital provides health in Amhara region services with 466 beds for inpatient at five wards and 14 outpatient wards and more than 672 health professionals.

\subsection{Study Design and Data Collection}

Hospital based cross-sectional study design was used to relate sociodemographic characteristics respondents, adverse drug reaction reporting systemand training on pharmacovigillance predictors of Nurses knowledge related to adverse drug reactionreporting forthis study among stratified proportional random sampling technique sampled 214. The structured questionnaire is compiled and adapted questions from different literatures and by considering the local situation.Data were collected by a self-administered questionnaire and collected within a maximum of 7 days and focuses on demographic characteristics and responses of Nurses to the knowledge related questions.

\subsection{Participant Eligibility Criteria}

To exclude bias, study participants for study 214 Nurses (62 and 152 in Finoteselam hospital and University of Gondar Teaching Hospital respectively).Nurses willing to participate, signing the written informed consent and working at Finote-selam Hospital and University of Gondar Teaching Hospitalwere involved.Based on the inclusion criteria and stratified sampling technique, out of 650health professionals, 214 were included in the study by considering confidence level of $95 \%$ with margin of error $5 \%$, and response rate of $100 \%$.

\subsection{Measures and Operational Definitions}

Independent variables and outcomes measures are defined as follow.

\subsubsection{Socio-Demographic and other Factors}

Socio-demographicvariables, such asage, sex, experience, profession, level of education andother factorsadverse drug reaction reporting system, and training on pharmacovigillance.

Nurses regarding to adverse drug reaction reporting system were responded as to Head of the pharmacy department, to Food, Medicine, and Health Care Administration and control authority, to hospital Drug and Therapeutic committee. Participants working at Finote Selam hospital and University of Gondar Teaching Hospitalselected in the category of respondent space.Nurses were asked participated in training related to adverse drug reaction reporting and /or pharmacovigillance.

\subsubsection{Nurses Knowledge Regarding Adverse Drug Reaction Reporting}

For the assessment of knowledge about adverse drug reactionreporting, already prepared 6 structured questions. Each correct question corresponded to 1 point, and incorrect one is 0 . There was a total of 6 points for the 6 questions. For the purpose of thisstudy,respondents were considered to have adequate knowledge if they scored $\geq 5$ out of 6 . They were considered to have inadequate knowledge if they scored below 5 out of 6 .

For the purpose of this studythe following terms were defined below:

Nurse - a person trained to care for the sick or infirm, especially in a hospital consists of clinical nurse, dentists, midwife nurse, physiotherapy nurse, Anesthetics nurse, Health officers and Ophthalmology nurse working atFinote-selam hospital and University of Gondar Teaching 
Hospital.

Knowledge-the ability of Nurses to give response on adverse drug reaction, adverse drug reaction reporting and reporting system related questions.

\subsection{Data Analysis}

The collected quantitative data were coded, cleared and checked for completeness, then entered and analyzed using Statistical Package for the Social Sciences (SPSS) version 20.0 statistical software. Binary logistic regression was used to determine inadequate knowledge. Odds ratio was used to determine significance and $95 \%$ confidence interval was calculated. Thosevariables in multivariate analysis with a $\mathrm{P}$ value $<0.05$ were used independent predictors for inadequate knowledge ofadverse drug reaction reporting.

\subsection{Ethical Considerations}

Ethical clearance and approval of the study was obtained from Institutional review board of Jimma University. Subsequent permission was granted from the authorities of University of Gondar Teaching Hospital. In addition each participant was asked a written consent before data collection. Participation of Nurses in this study was entirely voluntary and confidential and private information was protected. Study subjects were assured that non participation didn't affect their work activities at the Hospital. The right of participants to withdraw was respected and names were not mentioned.

\section{Results}

\subsection{Demographic Characteristics of Health Professionals}

A total number of 214 Nurses filled and all returned the questionnaire within the stipulated time frame.

Table 1. Socio-demographic characteristics of respondents at FelegeHiwot referral Hospital andUniversity of Gondar Teaching Hospital, North west Ethiopia, 2013

\begin{tabular}{llll}
\hline $\begin{array}{l}\text { Demographic } \\
\text { characteristics(n=214) }\end{array}$ & Frequency & Percentage \\
\hline \multirow{3}{*}{ Age } & $18-25$ & 37 & 17.3 \\
& $26-35$ & 102 & 47.7 \\
Sex & $36-45$ & 75 & 35.0 \\
& Male & 92 & 43.0 \\
& Female & 122 & 57.0 \\
Institution & Finote selam & 62 & 29.0 \\
& hospital & & \\
& University of & 152 & 71.0 \\
Level of & Gondar Teaching & & \\
education & Hospital & 152 & 71.0 \\
& Nurse , degree & 62 & 29.0 \\
\multirow{2}{*}{ Experience } & Diploma Nurse & 103 & 48.1 \\
& 0-5years & 88 & 41.1 \\
& 6-10years & 19 & 8.9 \\
& 10-15 years & 4 & 1.9 \\
\hline
\end{tabular}

As can be seen on table 1, mean age of the respondents 21.8 years $(\mathrm{SD}=7.01)$. A total of $122(57.0 \%)$ of the respondents were females, $152(71.0 \%)$ participants' level of education were bachelor of Nurse. The participants mean of experience were 1.64( $\mathrm{SD}=4.7)$ years.

As presented in table 2, Even if 212(99.1\%) participants knew the term adverse drug reaction, only $32(25.0 \%)$ respondents know how to report adverse drug reactions. most of participants i.e. $120(56.1 \%)$ and $37(17.35 \%)$ responded for possible factor (s) that may predispose(s) a patient to adverse drug reactionwere dispensing error and Non adherence to drug regimen, respectively.

Only $46(21.5 \%)$ respondents were knownabout the term pharmacovigillance. One hundred sixty eight $(78.5 \%)$ of Nurses weren't believe all the drugs available in the market are safe. More than half participant weren't seen drug reaction reporting format of Ethiopia and thought that adverse drug reaction is the same as with side effect. More participants responded that adverse drug reactions should be reported only when they are serious and life threatening. Pharmacy Personnels were primarily responsible to remind and follow up patients about adverse drug reaction of drugs. One hundred fifty two $(57.0 \%)$ Nurses were responded that head of the pharmacy department for whom you report the encountered adverse drug reaction. Food, Medicine, Health Administration and control authority was regulatory body is responsible for monitoring of adverse drug reactions answered by $183(85.5 \%)$, and only $20(9.3 \%)$ participants answered that this system created awareness of adverse drug reaction reporting in you. More participants worried about legal problems while they think of adverse drug reaction reporting. A standard text book was their source of information about adverse drug reaction140 (65.4\%).

\subsection{Knowledge of Nurses Regarding Adverse Drug Reaction Reporting}

Out of 214 participants, 14 (25.7\%) had adequate knowledge on adverse drug reaction reporting, while significant proportion of health professionals, 200 (74.3\%) had inadequate knowledge on adverse drug reaction reporting. Bivariate analysis in the binary logistic regression model showed that level of agewas candidate for multivariate logistic analysis. However, other factors such as sex, experience, level of education, institution, participation training on adverse drug reaction or pharmacovigilance and to whom you report the encountered adverse drug reaction weren't candidate for multivariate logistic analysis.

Crude odds ratio results not listed in table 3, due to from categories of level of education, experience and to whom you report the encountered adverse drug reaction zero values adequate knowledge and/or inadequate knowledge (Table 3). 
Table 2. ParticipantsKnowledge related questions on adverse drug reaction reporting of respondents at Felege-Hiwot referral Hospital andUniversity of Gondar Teaching Hospital, North west Ethiopia, 2013

\begin{tabular}{|c|c|c|c|}
\hline Variables & & Frequency & Percentage \\
\hline \multirow{2}{*}{ Do you know the term adverse drug reaction? } & Yes & 212 & 99.1 \\
\hline & No & 2 & .9 \\
\hline \multirow{7}{*}{$\begin{array}{l}\text { What possible factor (s) do you think predispose(s) a } \\
\text { patient to adverse drug reaction? }\end{array}$} & Dispensing error & 120 & 56.1 \\
\hline & Over dose & 25 & 11.7 \\
\hline & Prescription error & 9 & 4.2 \\
\hline & Life style of the patient & 18 & 8.4 \\
\hline & Non adherence to drug regimen & 37 & 17.3 \\
\hline & All of the above & 4 & 1.9 \\
\hline & None of the above & 1 & .5 \\
\hline \multirow{2}{*}{ Do you know the term Pharmacovigillance? } & Yes & 46 & 21.5 \\
\hline & No & 168 & 78.5 \\
\hline \multirow{2}{*}{$\begin{array}{l}\text { Do you believe all the drugs available in the market are } \\
\text { safe? }\end{array}$} & Yes & 49 & 22.9 \\
\hline & No & 165 & 77.1 \\
\hline \multirow{5}{*}{$\begin{array}{l}\text { Have you seen adverse drug reaction reporting format of } \\
\text { Ethiopia? } \\
\text { Do you think that adverse drug reaction is the same as with } \\
\text { side effect? }\end{array}$} & Yes & 70 & 32.7 \\
\hline & No & 144 & 67.3 \\
\hline & Yes & 65 & 30.4 \\
\hline & No & 149 & 69.6 \\
\hline & Serious and life threatening & 149 & 69.6 \\
\hline \multirow{4}{*}{$\begin{array}{l}\text { Adverse drug reactions should be reported only when they } \\
\text { are }\end{array}$} & Severe and cause disability & 35 & 16.4 \\
\hline & Mild and cause less inconvenience & 15 & 7.0 \\
\hline & All of the above & 15 & 7.0 \\
\hline & None of the above & 149 & 69.6 \\
\hline \multirow{4}{*}{$\begin{array}{l}\text { Which products are usually reported oradverse drug } \\
\text { reaction? }\end{array}$} & Prescription drugs & 168 & 78.5 \\
\hline & Over-the-counter drugs & 16 & 7.5 \\
\hline & Medical device & 1 & .5 \\
\hline & All the above & 29 & 13.6 \\
\hline \multirow{4}{*}{$\begin{array}{l}\text { Who do you think is primarily responsible to remind and } \\
\text { follow up patients about adverse drug reaction of drugs } \\
\text { they are given? }\end{array}$} & Pharmacy Personnels & 152 & 71.0 \\
\hline & Physicians & 3 & 1.4 \\
\hline & Nurses & 1 & .5 \\
\hline & All of the above & 58 & 27.1 \\
\hline \multirow{3}{*}{ Do you know how to report adverse drug reactions? } & Yes & 32 & 15.0 \\
\hline & No & 182 & 85.0 \\
\hline & To Head of the pharmacy & 152 & 71.0 \\
\hline \multirow{3}{*}{$\begin{array}{l}\text { To whom you report the encountered adverse drug } \\
\text { reaction? }\end{array}$} & $\begin{array}{l}\text { To Food, Medicine, and Health Care } \\
\text { Administration and control authority }\end{array}$ & 22 & 10.3 \\
\hline & To hospital Drug and Therapeutic committee & 21 & 9.8 \\
\hline & All of the above & 19 & 8.9 \\
\hline \multirow{5}{*}{$\begin{array}{l}\text { In Ethiopia, which regulatory body is responsible for } \\
\text { monitoring of adverse drug reactions reporting? }\end{array}$} & $\begin{array}{l}\text { Food, Medicine, Health Administration and } \\
\text { control authority }\end{array}$ & 183 & 85.5 \\
\hline & Ethiopian pharmaceutical association & 1 & .5 \\
\hline & Federal ministry of health & 18 & 8.4 \\
\hline & Pharmaceutical fund and supply agency & 8 & 3.7 \\
\hline & All of the above & 4 & 1.9 \\
\hline \multirow{2}{*}{$\begin{array}{l}\text { Has this system created awareness of adverse drug reaction } \\
\text { reporting in you? }\end{array}$} & Yes & 20 & 9.3 \\
\hline & No & 194 & 90.7 \\
\hline \multirow{3}{*}{$\begin{array}{l}\text { Do you worry about legal problems while you think of } \\
\text { adverse drug reaction reporting? }\end{array}$} & Yes & 116 & 54.2 \\
\hline & No & 98 & 45.8 \\
\hline & $\begin{array}{l}\text { National drug formulary and Standard } \\
\text { Treatment Guideline }\end{array}$ & 54 & 25.2 \\
\hline \multirow{4}{*}{$\begin{array}{l}\text { What is your source of information about adverse drug } \\
\text { reaction? }\end{array}$} & Standard text books & 140 & 65.4 \\
\hline & Notes from the training & 6 & 2.8 \\
\hline & Internet & 8 & 3.2 \\
\hline & Drug information centers & 6 & 2.8 \\
\hline \multirow{4}{*}{$\begin{array}{l}\text { Which method would you prefer to send adverse drug } \\
\text { reaction reporting? }\end{array}$} & Telephone & 45 & 21.0 \\
\hline & Internet & 138 & 64.5 \\
\hline & Post & 28 & 13.1 \\
\hline & I don't know & 3 & 1.4 \\
\hline
\end{tabular}

Accordingly, in the multivariate logistic analysisage was retained as significant factor for inadequate knowledge towardsadverse drug reactionreporting i.e agecategorized as
26-35 years was 10.4 times more likely inadequate knowledge $\mathrm{AOR}=10.4,95 \% \mathrm{CI}=86.423-1.251, \mathrm{P}=0.030$ (Table 3). 
Table 3. Binary and multivariable logistic regression model predicting the association of between knowledge and different variables atFelege-Hiwot referral Hospital andUniversity of Gondar Teaching Hospital, North west Ethiopia, 2013.

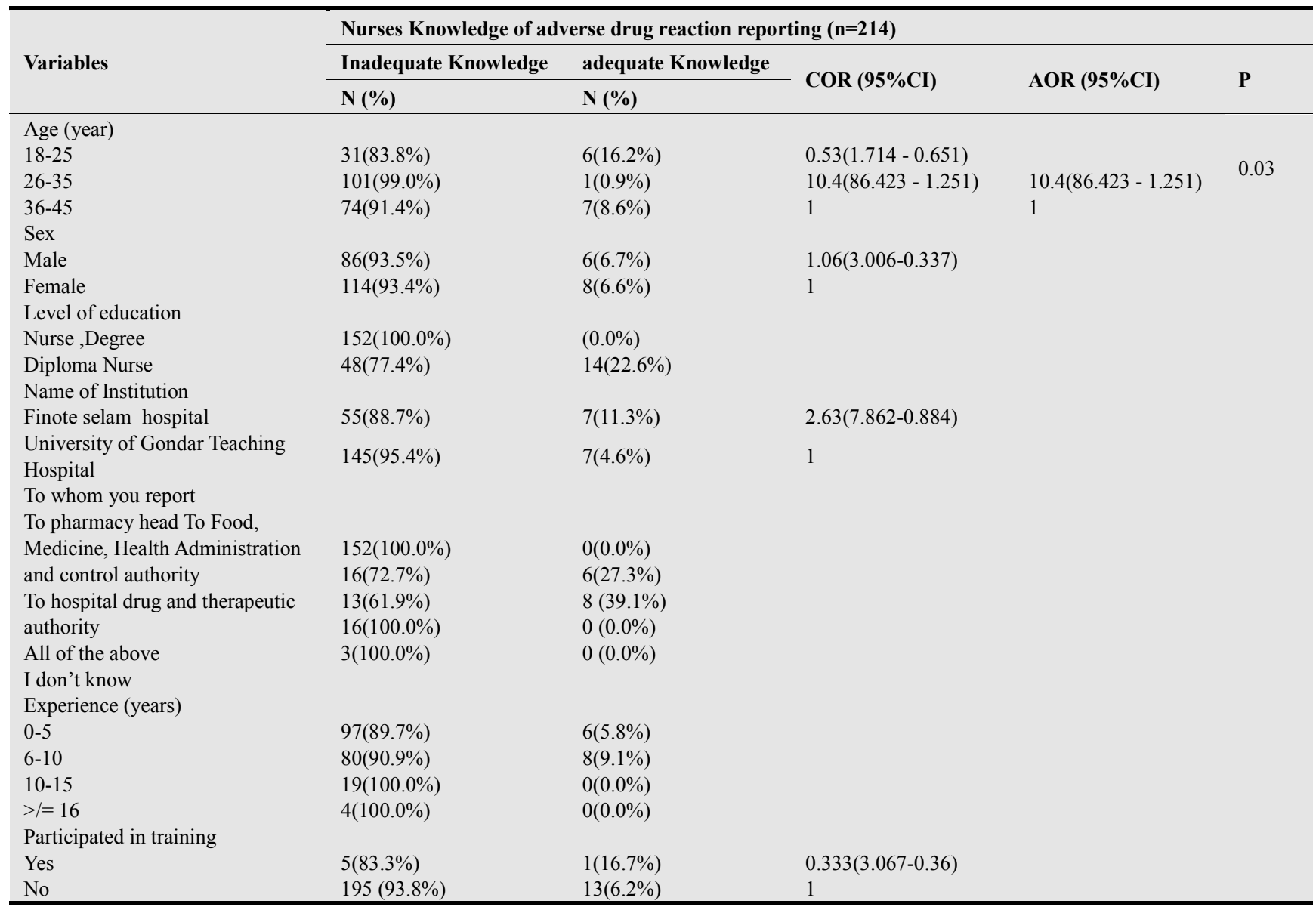

\section{Discussion}

In the present study several important findings were obtained and only $14(25.7 \%)$ of participants were adequate knowledgewhich is in congruence with the study in selected health facilities of Jimma zone, south west Ethiopia $23.17 \%$ had adequate knowledge(11). Limited knowledge of adverse drug reactionreporting may reduce the number of reports submitted to Food, Medicine, Health Administration and control authority byhealth professionals, which in turn could delay the identification of drug hazards and reduce the likelihood of warnings being generated about unexpected and uncommon adverse drug reactions. The results of this study suggest that greater effort is needed to improve adverse drug reaction reporting among Nurses worked atFelege-Hiwot referral Hospital andUniversity of Gondar Teaching Hospital. The questions of what predicts inadequate knowledge on adverse drug reaction reporting has not been answered rationally in study area. In the present study, the possible factors related to inadequate knowledge on adverse drug reaction reporting among 200(74.73\%) of the participants have been identified using multiple logistic regression analysis. Age was independent predictor for inadequateknowledge.

The present study showed that age of the participants was a significantly associated with knowledge and identified as one of the independent predictor of inadequate knowledge. Participants with the age category of 26-35 years were 10.4times more likely inadequate knowledge towards adverse drug reaction reporting as compared to those who were in the age category of 36-45. Why this factor was associated with inadequate knowledge is unclear, probably this age groups of health professionals could be busy life schedule and/or less interaction with patients. Similarly research that agreed to this finding that conducted inDar Es Salaam, Tanzania Community Pharmacy Dispensers aged 50 years and above were more knowledgeable about adverse drug reactions reporting than those aged below 50 years(12). Differently to this finding, a study in Texas, America the lack of knowledge was found to be more acute among older ( $>38$ years) pharmacists (13). Studies that takes placed at China(7), Northern India(8) and Italy(9) had inadequate knowledge on adverse drug reaction reporting. This however contradicts the findings as reported at UK(14), Nigeria(15), and Australia(16).

Lack of knowledge on what is to be reported, who should report, when to report, how to report where to report, together with unavailability of adverse drug reactions reporting forms influenced the practice towards adverse drug reactions reporting among health professionals. Two 
hundred twelve (99.1\%) of participantswere aware of the term "adverse drug reactions", but only $46(21.5 \%)$ respondents aware of the term "pharmacovigillance." Studies in South West Ethiopia(11) and Ethiopia(10) of the respondent knew the term pharmacovigilance $(19.51 \%)$ and $45.3 \%$ respectively.One hundred sixty eight $(78.5 \%)$ Nurses stated that all drugs available in the market are not safe, but only $32(25.0 \%)$ indicated that they do not know how to report adverse drug reactions. A study from Italy reported that doctors had little information concerning adverse drug reactions and adverse drug reaction reporting systems (17). Of 214the participants, more than half participant did not know the format in which adverse drug reactions are reported, in congruence with a study in south west Ethiopia $25.61 \%$ Nurses knew the availability of adverse drug reaction reporting format(11). This might be due to inadequate promotion of reporting form and weak regulatory body contact with the health facilities in general and the Nurses in particular. More than half participants, think thatadverse drug reaction is the same as with side effect, but opposite of a study in South West Ethiopia 79.27\% of participants said that adverse drug reaction was different from side effect(11). According to WHO recommendation, in order to avoid inflating of the figures of drug induced diseases; it is convenient to retain the term side effect for minor effects which are related to the pharmacological properties of the drug(18). This might lack of adequate information regarding adverse drug reaction in the curricula and/ or trainings.

One hundred twenty $(56.1 \%)$ responded for possible factor (s) that may predispose(s) a patient to adverse drug reactionwere dispensing error.These results showed that south west of Ethiopia Nurses are more familiar with $(39.03 \%)$ of them replied that dispensing error was the primary factor predisposing to adverse drug reactions. This might be due to the fact that dispensers are the expected Nurses to know more about drug properties including their adverse effects than other professionals and as a result they are expected to remind the patients about drugs than other health professionals(11). Thirty seven $(17.35 \%)$ of them also believed that drug non adherence to the drug regimen was the primary factor predisposing adverse drug reactions. From this, we can understand that respondentshad inadequate knowledge on factor (s) that may predispose(s) a patient to adverse drug reaction.

One hundred forty nine (69.6\%) participants stated that serious and life threatening reactions should be reported. A research conducted inDar Es Salaam respondents, majority (60.3\%) agreed that reporting is necessary for serious adverse drug reactions(12). A study in Texas, America $43.3 \%$ of the pharmacists thought that all adverse drug events, regardless of severity, should be reported to food and drug authority of America(13).On the contrary, a study done inPortugal on serious adverse drug reactions should not be reported (19).

One hundred sixty eight (78.5\%) Nurses believed that all prescription drugs, should usually reported foradverse drug reaction. A study conducted in Ethiopia 24\% of the responders believed that only adverse drug reaction of prescription drugs need to be reported whereas most of them don't think so (69\%) (20).

One hundred fifty two $(57.0 \%)$ agreed that pharmacy personnels were primarily responsible to remind and follow up patients about adverse drug reaction of drugs they are given. A study in Ethiopia 15.3\%providers response believe that it is the responsibility of the pharmacist/druggist (20).

One hundred fifty two (57.0\%)participants agreed that the encountered adverse drug reaction would be reported to head of the pharmacy department. A study conducted in south West Ethiopia (46.34 \%) of the respondents believed that adverse drug reaction should be reported to drug administration and control authority $(30.49 \%)$ to drug and therapeutic authority, and $19 \%$ to the pharmacy department of the respective health facilities(11). It is obviously known that among the major activities of head of the pharmacy department, drug and therapeutic authority and Food, Medicine, Health Administration and control authority was monitoring adverse drug reaction in the health facilities.

One hundred eighty three $(85.5 \%)$ participantsknew the regulatory body responsible for monitoring of adverse drug reactions i.e. Food, Medicine, Health Administration and control authority of Ethiopia. This might be due to adequate promotion on widened responsibilities in addition to drug monitoring. But only 194 (80.7\%) Nurses agreed that, this sector definitely not created awareness on adverse drug reaction reporting. This might be due to inadequate promotion of reporting system and weak regulatory body contact with the health facilities in general and the Nurses in particular. One study in south west Ethiopia showed that $183(85.5 \%)$ of the Nurses knew the availability of national adverse drug reaction reporting system(11). A study done in Lagos, Nigeria on perception of doctors to adverse drug reaction reporting showed that $40.4 \%$ of the respondent knew about existence of National Pharmacovigilance center in their country $(8,21)$.

One hundred sixteen $(54.2 \%)$ participants admitted that they were worried about legal problems while adverse drug reaction reporting. Equivalently $46.49 \%$ doctors in Hyderabad, India admitted that they were worried about legal problems while adverse drug reaction reporting(22).

One hundred forty $(65.4 \%)$ respondents stated that standard text book was their source of information for adverse drug reaction reporting. More than half, 138(64.5\%) participants preferred E-mail as their method to send adverse drug reaction reporting. A study done in South West Ethiopia 78.05\% used National Drug Formulary and Standard Treatment Guidelines as sources of information on adverse drug reactions information on drugs (11).

Although this study has strength like high response rate, questionnaire was pretested, it has some limitations; since the study is a cross-sectional, and it has a limitation to formulate a casual association, as to how and when the associations are established. 


\section{Conclusion}

Vast majority of respondents had inadequate knowledge might lead to not reporting the encountered adverse drug reaction. This could delay signal detection of adverse drug reaction. So it requires urgent attention for enhanced safety of the patients and society at large.

\section{Acknowledgments}

Author would like to extend appreciations to individuals who involved indata collection and physicians, pharmacy personnel and nurses who willingly gave us all the information.

\section{References}

[1] New rules for reporting in European union, Article 114 and Article 168(4)(c) (2010).

[2] Patel KJ, Kedia MS, Bajpai D, Mehta SS, Kshirsagar NA, Gogtay NJ. Evaluation of the prevalence and economic burden of adverse drug reactions presenting to the medical emergency department of a tertiary referral centre: a prospective study. BMC Clin Pharmacol. 2007;7:8.

[3] RA. K. Adverse drug reaction may be a leading cause of death in US. 1998.

[4] Mehta U, Durrheim DN, Blockman M, Kredo T, Gounden R, Barnes KI. Adverse drug reactions in adult medical inpatients in a South African hospital serving a community with a high HIV/AIDS prevalence: prospective observational study. $\mathrm{Br} \quad \mathrm{J}$ Clin Pharmacol. 2008 Mar;65(3):396-406.

[5] Dawit Dilbato ZG, Shiferaw Teklemariam. A base line survey on prescribibng indicators and factors influencing prescribing in Southern Ethiopia. Ethiop J Health Dev. 1998;12(2):87-93.

[6] Aklillu E, Persson I, Bertilsson L, Johansson I, Rodrigues F, Ingelman-Sundberg M. Frequent distribution of ultrarapid metabolizers of debrisoquine in an ethiopian population carrying duplicated and multiduplicated functional CYP2D6 alleles. J Pharmacol Exp Ther. 1996 Jul;278(1):441-6.

[7] Li Q, Zhang SM, Chen HT, Fang SP, Yu X, Liu D, et al. Awareness and attitudes of healthcare professionals in Wuhan, China to the reporting of adverse drug reactions. Chin Med J (Engl). 2004 Jun;117(6):856-61.

[8] Rehan HS, Vasudev K, Tripathi CD. Adverse drug reaction monitoring: knowledge, attitude and practices of medical students and prescribers. Natl Med J India. 2002 JanFeb;15(1):24-6.

[9] Cosentino M, Leoni O, Banfi F, Lecchini S, Frigo G. Attitudes to adverse drug reaction reporting by medical practitioners in a Northern Italian district. Pharmacol Res. 1997 Feb;35(2):85-8.
[10] plus/SPS DAaCAicwMR. Report on the assessment of health care providers' knowledge, attitude and practice on Adverse drug reaction (adverse drug reaction) reporting and its monitoring. Addis Ababa, Ethiopia: drug administeration and control authorityAugust, 2008.

[11] Mulugeta T.Angamo AT, Nasir Tajure Wabe. Knowledge, Attitude and Practice of Adverse drug reaction Reporting among Health Professionals in Southwest Ethiopia]. TAF Prev Med Bull. .2011;23.11.2011:1-10.

[12] Shimwela GMoo. Adverse drug reaction Reporting Knowledge, Attitude and Practices of Community Pharmacy Dispensers [Partial Fulfillment of the Requirements for the MSc Programme]. DAR ES SALAAM, TANZANIA: Muhimbili University of Health and Allied Sciences; 2011.

[13] Paul Gavaza CMB, Kenneth A. Lawson, Karen L. Rascati, James P. Wilson, and Mary Steinhardt. Texas pharmacists' knowledge of reporting serious adverse drug events to the Food and Drug Administration. J Am Pharm Assoc. 2011;51:397-403.

[14] Evans SM, Berry JG, Smith BJ, Esterman A, Selim P, O'Shaughnessy J, et al. Attitudes and barriers to incident reporting: a collaborative hospital study. Qual Saf Health Care. 2006 Feb;15(1):39-43.

[15] Okezie EO, Olufunmilayo F. Adverse drug reactions reporting by physicians in Ibadan, Nigeria. Pharmacoepidemiol Drug Saf. 2008 May;17(5):517-22.

[16] Green CF MD, Rowe PH, Pirmohamed M. Attitudes and knowledge of hospital pharmacists to adverse drug reaction reporting. Br J Clin Pharmacol. 2001;51(1):81-6.

[17] Subish P IM, Mishra P. Evaluation of the knowledge, attitude and practices on adverse drug reactions and pharmacovigilance among healthcare professionals in a Nepalese hospital: a preliminary study. The Internet Journal of Pharmacology. 2008; 61 (1).

[18] WHO. Drug related morbidity and mortality;Updating the cost of illness model. Journal of American Medical Association. 2001.

[19] Herdeiro MT FA, Polonia J, Gestal-Otero JJ Influence of Pharmacists' attitudes and adverse drug reaction reporting: a case control study in Portugal. Drug Saf. 2006;29 (4):331-40.

[20] plus/SPS DAaCAicwMR. Report on the assessment of health care providers' knowledge, attitude and practice on Adverse drug reaction (adverse drug reaction) reporting and its monitoring 2008.

[21] Oshikoya KA, Awobusuyi JO. Perceptions of doctors to adverse drug reaction reporting in a teaching hospital in Lagos, Nigeria. BMC Clin Pharmacol. 2009;9:14.

[22] RAJESH A KAMTANE VJ. Knowledge, Attitude and Perception of Physicians towards Adverse drug reaction Reporting: A Pharmaco-epidemiological Study. Asian J Pharm Clin Res. [Academic Sciences]. 2012;5(3). 